\title{
Tree Species Composition and Structure near Road Borders in the Laurel Forest of Anaga (Tenerife - Islas Canarias)
}

\author{
Zaira NEGRÍN, José Ramón ARÉVALO* \\ Departamento de Botánica, Ecología y Fisiología Vegetal, Universidad de La Laguna, Astrofisico \\ Francisco Sánchez Street, 2, 38206 San Cristóbal de La Laguna, Santa Cruz de Tenerife, Spain \\ * corresponding author: jarevalo@ull.edu.es \\ Bulletin UASVM series Agriculture 73(2)/2016 \\ Print ISSN 1843-5246; Electronic ISSN 1843-5386 \\ DOI 10.15835/buasvmcn-agr: 12398
}

\begin{abstract}
Urbanization is one of the main causes of species extinction. Closely linked to urbanization are road systems, which are a source of biotic and abiotic effects on the surrounding landscape. The continued existence of these corridors results in enormous human activity (Forman \& Alexander, 1998). In particular, roads sharply define and fragment forest ecosystems leading to changes in plant species composition and vegetation structure from road border to the surrounding interior.

This paper assesses border effects on tree species richness and composition in the laurel forest of Anaga, Tenerife, Spain. Effects of anthropogenic corridors on vegetation differed among the study sites. Multivariate analysis revealed that species composition is more related to the sampling site than to the effect of the corridor, while for density, significant differences were found between the road border and forest interior but not as a regular pattern. This suggests that main corridor disturbances regarding tree basal area is limited to the immediate road edge in the laurel forest, while for species composition, no significant differences were found.
\end{abstract}

Keywords: $D B H, D C A$, disturbances, edge effect, tree density

\section{INTRODUCTION}

Road systems have an impact on the forest plant community, defining sharp borders that delimit the forest matrix, and change species composition and structure from road edges to the surrounding interior (Ranney et al., 1981). Not only is species composition affected, but so are ecological processes by the presence of these human infrastructures (Matlack, 1994). A complete understanding of forest dynamics requires the study of these edge areas, where ecological processes differ from those occurring within the forest (Ranney et al., 1981).

Islands are fragile ecosystems prone to human direct or indirect alterations and are particularly susceptible to the introduction of alien species (Whittaker, 1998). Habitat fragmentation is also known to negatively affect native biotas through the invasion of exotic species (Suarez et al., 1998). Considering that Tenerife has increased its road surface by $400 \%$ in the last 80 years (Pulido and Utrilla, 1984, García et al., 1989), the island's native ecosystems may have suffered great alterations derived from area reduction and edge effects.

Our aim was to analyze the influence of road corridors in one of the most emblematic ecosystems of the Canary Islands: the laurel forest. We attempted to evaluate road edge effects on tree species composition and structure (density and basal area) in order to determine the extent of the effect of the road disturbance.

\section{MATERIAL AND METHODS}

The study was conducted in the Anaga Rural Park in the NE corner of Tenerife, Canary Islands $\left(28^{\circ} 19^{\prime} \mathrm{N}, 16^{\circ} 34^{\prime} \mathrm{W}\right)$. The park encompasses a 7 
to 8 million year- old basaltic massif (Ancochea et al., 1990) covering about $130 \mathrm{~km}^{2}$. The park represents $7 \%$ of Tenerife's total area. Today, only $10 \%$ of the forest remains, which has been formally protected since 1988, currently experiencing fewer human disturbances and no area reduction.

The annual precipitation of the park reaches $900 \mathrm{~mm}$, but can be twice this amount considering fog drip (Kämmer, 1974). The mean annual temperature is close to $15^{\circ} \mathrm{C}$ with minimal annual and daily fluctuations. There are no frost events. Two seasons can be differentiated, winter and summer, but in most years, differences between the two most extreme months are not large (Ceballos and Ortuño 1976).

We selected the main paved road at El Moquinal, located at the centre of the Anaga Rural Park, which carries the most intense road traffic in the park. Four perpendiculars were randomly selected to the road beginning from the canopy of the last tree next to the road. Each plot was $30 \mathrm{x}$ $15 \mathrm{~m}$, and was divided into three transects of $10 \mathrm{x}$ $15 \mathrm{~m}$, and each transect was subdivided into three subplots $10 \times 5 \mathrm{~m}$, resulting in three subplots at 0 , 5 and $10 \mathrm{~m}$ distance from the road border.

Within each subplot, all tree species were identified ( $>2.5 \mathrm{~cm}$ diameter breast high; DBH) and noted DBH for the calculation of basal area and density. We looked for differences between these variables in the three subplots using as a factor the distance to the road border, using ANOVA.

Data normality was checked with the ShapiroWilk test and the homocedasticity of the data with a multiple F test. The post-hoc Tukey test was used to detect significant differences among groups for the different variables. Basic statistical methods followed Zar (1984) and were implemented using the SPSS statistical package (Anon, 1986).

Ordination techniques help to explain community variation (Gauch, 1982), and they can be used to evaluate trends over time as well as space. We used Detrended Correspondence Analysis (DCA; Hill and Gauch 1980, using CANOCO; ter Braak \& Šmilauer 1998) to examine how species composition changed over space and whether different classes could be identified from the analyses. Analyses were based on species basal area.

\section{RESULTS AND DISCUSSION}

Roads and trails are abrupt discontinuities, contrasting with the wider and more diffuse edges common to many natural areas (Delgado et al., 2001). These road effects can penetrate long distances into the forest and may alter the forest matrix in different ways (Forman \& Alexander, 1998) depending on the species.

In the case of basal area (Fig. 1), our results revealed non-significant differences between the border and the forest interior.

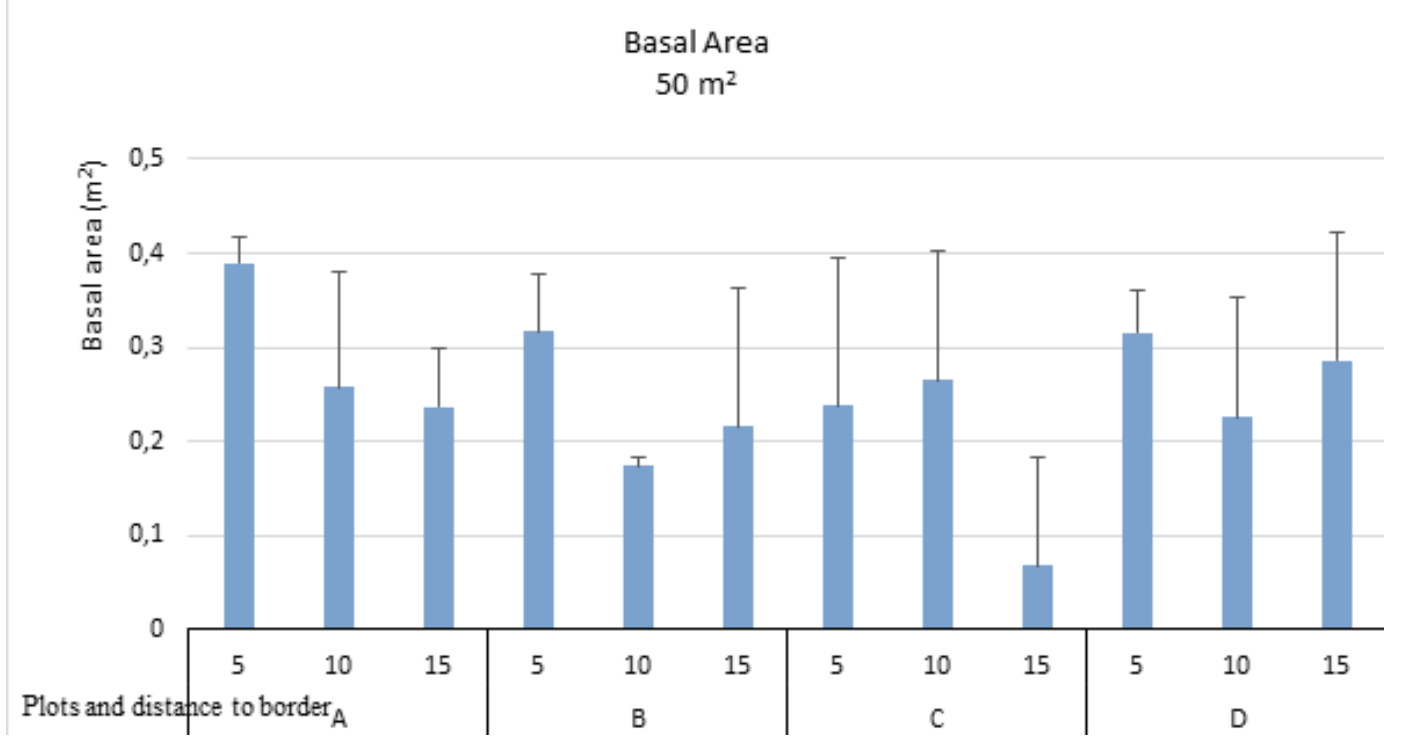

Fig. 1. Mean values and standard deviations for basal area at each site and border distance. Identical letters above the bars indicate non-significant differences $(p<0.05)$ : $A\left(F_{2,6}=3,080 ; p>0.05\right) B$

$$
\left(\mathrm{F}_{2,6}=1,859 ; \mathrm{p}>0.05\right), \mathrm{C}\left(\mathrm{F}_{2,6}=1,801 ; \mathrm{p}>0.05\right), \mathrm{D}\left(\mathrm{F}_{2,6}=0,516 ; \mathrm{p}>0.05\right)
$$




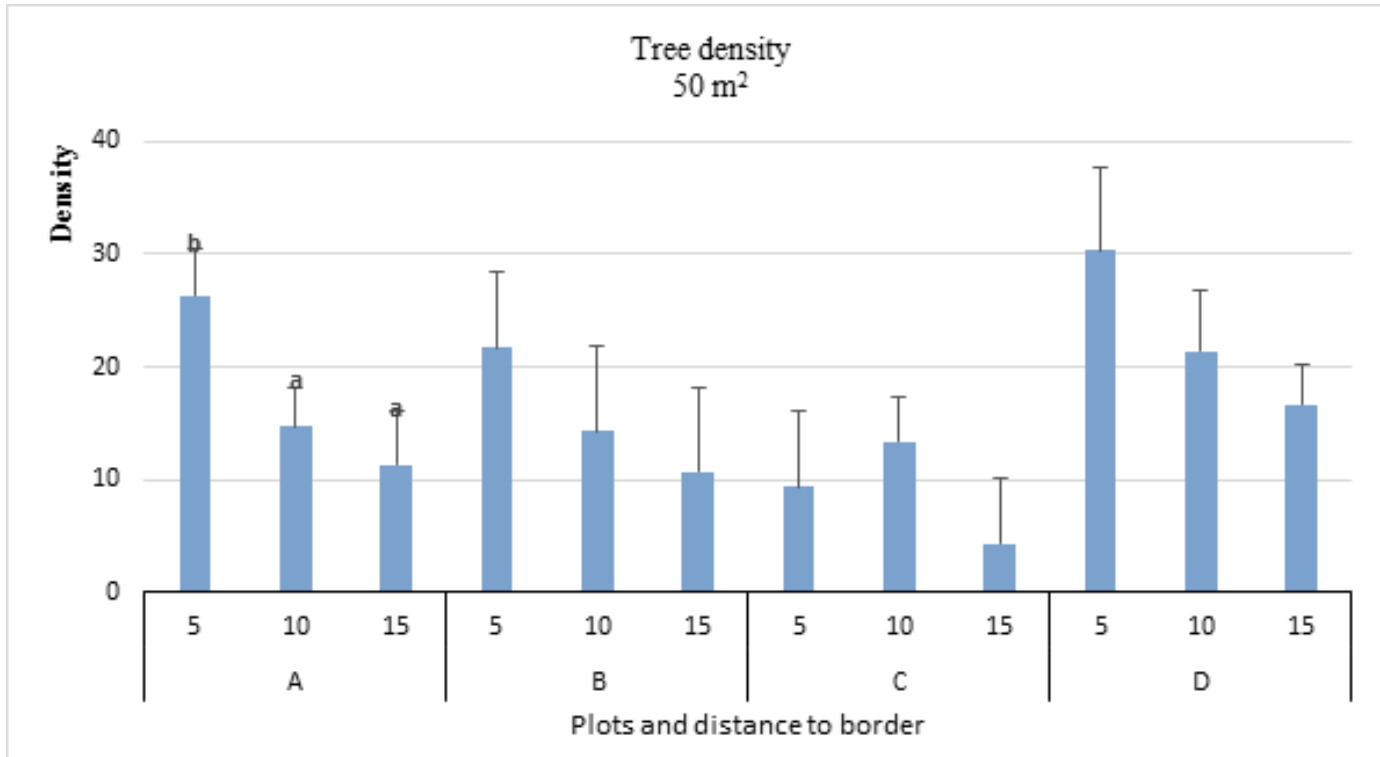

Fig. 2. Mean values and standard deviations for density at each site and border distance. Identical letters above the bars indicate non-significant differences $(\mathrm{p}<0.05): A\left(F_{2,6}=10,948 ; p<0.05\right) B$ $\left(F_{2,6}=1,765 ; p>0.05\right), C\left(F_{2,6}=1,926 ; p>0.05\right), D\left(F_{2,6}=4,572 ; p>0.05\right)$

The impact on trees is less relevant, this can be due to the previous presence of the trees to the building of the roads (in the case of the road analysed, it was built and paved around 70 years ago). In this case, more time will be necessary in order to find differences. Furthermore, the pattern of response to the road is different at the different sites, revealing non-consistent patterns in this case.

With respect to tree density, a more consistent pattern was found, with more individuals at plots near to the border than in the interior. Although these differences were only significant at one of the sites, they suggest a higher density at the border in relation to tree regeneration and different environmental characteristics of these plots due to the road: higher insolation, more nutrients, etc. (Arévalo et al., 2008).

In the case of tree species composition, the lack of differences is also evident, as there is no discrimination between the plots in the DCA analysis (Fig. 3).

The only notable information is that the polygon that enclosed the plots at $10 \mathrm{~m}$ distance is larger, indicating a more diverse species composition. However, as indicated before, there was practically no discrimination between plots based on distance indicating no differences in species composition.

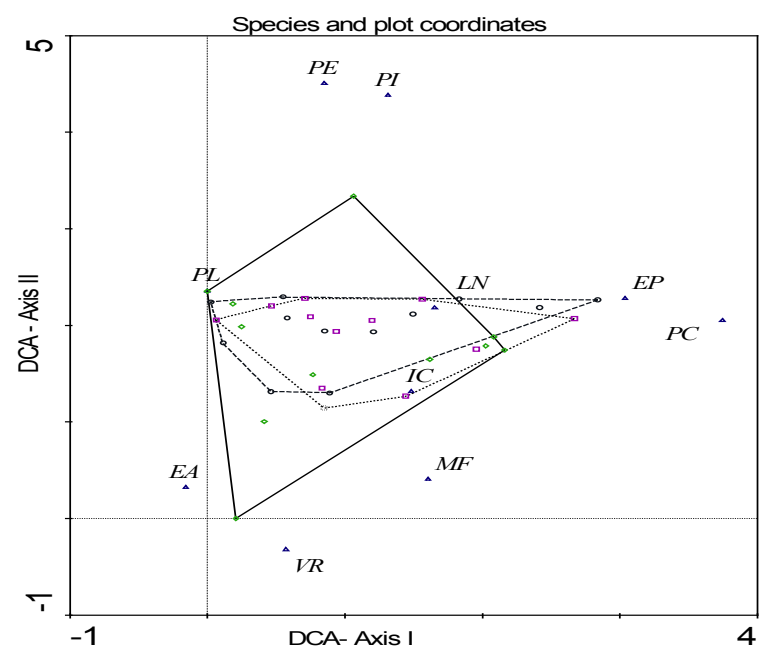

Fig. 3. Plot and species scores in the space defined by axis I and axis II of the DCA. Polygons enclose plots at the tree distances to the border (Polygon of dashed lines for $5 \mathrm{~m}$ distance to the border, dotted lines for 10 and solid line for $15 \mathrm{~m}$ ). Eigenvalues of axes I and II were 0.552 and 0.343 and the cumulative percentage of variance of both axes was 51.6\%).

Abbreviations for species are: Apollonias barbujana (AB), Erica platycodon (EP), Ilex canariensis (IC), Ilex perado (IP), Laurus novocanariensis (LN), Morella faya (MF), Ocotea foetens (OF), Persea indica (PI), Picconia excelsa (PE), Prunus lusitanica (PL), Rhamnus glandulosa (RG), Visnea mocanera (VM), Viburnum rigidum (VR) 
Roads in the Canary Island laurel forest permit visitor contact with relatively remote areas and allow local inhabitants to move across the territory. However, a deeper understanding of the effects of these anthropogenic corridors is required to ensure the value of these unique laurel forest remains (Kuiken, 1988).

In the case of tree species composition, the lack of differences is also evident, as there is no discrimination between the plots in the DCA analysis (Fig. 3). The only notable information is that the polygon that enclosed the plots at $10 \mathrm{~m}$ distance is larger, indicating a more diverse species composition. However, as indicated before, there was practically no discrimination between plots based on distance indicating no differences in species composition.

\section{CONCLUSION}

Roads in the Canary Island laurel forest permit visitor contact with relatively remote areas and allow local inhabitants to move across the territory. However, a deeper understanding of the effects of these anthropogenic corridors is required to ensure the value of these unique laurel forest remains (Kuiken, 1988).

\section{REFERENCES}

1. Ancochea E, Fúster JM, Ibarrola E, Cendrero A, Coello J, Hernán F, Cantagrel JM, Jamond C. (1990). Volcanic evolution of the island of Tenerife (Canary Islands) in the light of new K AR data. J. Volc. Geotherm. Res., 44: 231249.

2. Anon. (1986). SPSS/PC+ V.6.0. Base manual. SPSS Inc., Chicago, IL.
3. Arévalo JR, Delgado JD, Fernández-Palacios JM (2008). Changes in species composition and litter production in response to anthropogenic corridors in the laurel forest of Tenerife (Canary Islands). Plant Biosystems, 142: 614-622.

4. Ceballos L., Ortuño F. (1974) Vegetación y flora forestal de las Canarias Occidentales. 20 Ed. Cabildo Insular de Tenerife, Santa Cruz de Tenerife.

5. Delgado JD, Arévalo JR, Fernández-Palacios JM (2001). Assessing road edge effect for an introduced predator: rats and forests in Tenerife (Canary Islands). Ecography, 24: $539-546$

6. Gauch, HGJr. (1982). Multivariate analysis in community ecology. Cambridge University Press, Cambridge.

7. Hill MO, Gauch HJr. (1980). Detrended Correspondence Analysis: an improved ordination technique. Vegetatio, 42: 47-58.

8. Kämmer F (1974) Klima und vegetation auf Tenerife, besonders in Hinblick auf den Nebelniederschlag. Scripta Geobot., 7: 1-78.

9. Kuiken M (1988). Consideration of environmental and landscape factors in highway planning in valued landscapes: An Australian survey. J. Environ. Manage., 26: 191-201.

10. Ranney JW, Bruner MC, Levenson JB (1981). The importance of edge in the structure and dynamics of forests islands. In: Burgess RL, Sharpe DM, editors. Forest islands in man dominated landscapes, Springer Verlag, New York, 67-69.

11. Suarez AV, Bolger DT, Case TJ (1998). Effects of fragmentation and invasion on native ant communities in coastal southern California. Ecology 79:2041 2056.

12. Matlack, G. R. (1994) Vegetation dynamics of the forest edge trends in space and successional time. Journal of Ecology, 82: 113-123.

13. Pulido T, Utrilla L (1984). El transporte. Geografía de Canarias (ed. Afonso), 10-14. Interinsular Canaria, Santa Cruz de Tenerife.

14. García M (1989). El bosque de la laurisilva en la economía guanche. Aula de Cultura de Tenerife 12. Cabildo Insular de Tenerife, Santa Cruz de Tenerife.

15. Whittaker RJ (1998). Island Biogeography. Ecology, Evolution and Conservation. Oxford University Press, Oxford, UK. 